\section{Pupil assessment in optic nerve disorders}

FD Bremner

Uses in clinical practice Pupil assessment is invaluable when distinguishing functional from organic visual loss. Its usefulness in distinguishing between different causes of optic neuropathy and as a prognostic sign is gradually emerging.

Eye (2004) 18, 1175-1181. doi:10.1038/sj.eye.6701560

Keywords: pupil; optic nerve; reflex; afferent defect; perimetry

\section{Introduction}

Reflexes are extensively used in clinical neurology to assess function in sensory or motor nerves. Reflexes are involuntary and therefore serve as objective indicators of function. The optic nerve forms the afferent limb of a number of brainstem reflexes that could potentially be exploited when testing its function, but the most useful has proved to be the pupil light reflex (PLR): the PLR can be easily observed, causes no distress or discomfort to the patient, and may be quantified. Moreover, the symmetry of the PLR to stimulation of either eye provides an opportunity to compare the pupillomotor drive in both eyes.

\section{History}

Galen of Pergamon is credited as the first physician to make clinical use of the PLR in the second century (common era). ${ }^{1}$ When deciding whether or not to couch a cataract he would cover and then uncover each eye in turn while the patient gazed out of the window: covering the fellow eye produced disproportionate pupillary dilation when the cataractous eye had retrolental pathology. The association of PLR attenuation and optic nerve disease was not made until the end of the 19th century when Hirschberg $^{2}$ described a woman with acute visual loss. In view of the normal fundus appearance, her visual loss was initially thought to be hysterical, but demonstration of the absent PLR on the affected side confirmed the different subpopulations of optic nerve fibres. Less is known of the relationship electrodiagnostic tests.
Department of Neuroophthalmology (Box 142) National Hospital for Neurology \& Neurosurgery Queen Square London WC1N 3BG UK

Correspondence:

FD Bremner

Department of Neuroophthalmology (Box 142) National Hospital for Neurology \& Neurosurgery Queen Square

London WC1N 3BG UK Tel: +4420 78373611 ext.3382

Fax: + 442076762041

E-mail: fionbremner@ doctors.org.uk

Received: 4 September 2003

Accepted: 4 September 2003 
diagnosis of retrobulbar optic neuropathy. After 20 years, Gunn $^{3}$ published a series of cases in which he claimed to have been able to distinguish organic lesions from malingering on the basis of comparing pupillary escape (pupil dilation after prolonged light stimulation) in the two eyes. Kestenbaum devised a means of quantifying this phenomenon in his textbook ${ }^{4}$ and coined the term 'Marcus Gunn pupil' to describe such an afferent pupil defect. Today, this eponym has largely disappeared but observation of the PLR has become an essential element in the examination routine for any patient with suspected optic nerve disease.

\section{Clinical techniques}

A number of techniques for testing the PLR have entered clinical practice. The original method for detecting an afferent pupil defect was Galen's cover/uncover test. This is based on the principle that when a patient looks at a diffuse but directional light source (eg the window), both pupils dilate very slightly if one eye is covered because the total pupillomotor drive has been reduced. In healthy subjects, a similar degree of pupil dilation is observed no matter which eye is covered, whereas in unilateral or asymmetric optic nerve disease the pupil dilation is greater when the 'good' eye is covered. It is a quick and simple test requiring no special equipment, but has disappeared from the modern clinical repertoire because it is impractical (we no longer have open windows to gaze through) and relatively insensitive., Moreover, the test requires two working pupils, it is qualitative and because a comparison is being made, it is therefore of no use in bilateral (symmetrical) disease.

The swinging flashlight test was first described by Levatin in $1959^{7}$ and subsequently formalized by Thompson. ${ }^{8,9}$ Like the cover/uncover test, it is a technique for comparing the pupillomotor drive in the two eyes; unilateral or asymmetric optic nerve disease is associated with constriction of both pupils when the flashlight is shone in the good eye but dilation of both pupils when the flashlight is shone in the bad eye. Relative afferent pupil defects (RAPD) as small as $3 \mathrm{~dB}$ can be detected clinically, and sensitivity can be further enhanced by placing a $3 \mathrm{~dB}$ neutral density filter (NDF) in front of the suspected bad eye to widen the intereye difference in pupillomotor drive to a detectable level. ${ }^{10}$ The degree of RAPD can be easily quantified by placing $\mathrm{NDF}^{11}$ crossed polarizing filters, ${ }^{12-14}$ or Bagolini filters ${ }^{15}$ of increasing value in front of the good eye until the RAPD is neutralized.

The swinging flashlight test is now the most common pupil test in clinical practice. Like the cover/uncover test, it is quick and low-tech, but it has the additional advantages of requiring only one working pupil, is easily quantifiable, and much more sensitive. The test is deceptively simple, however, and requires considerable practice to perform reliably as well as care in its interpretation; inexperienced clinicians may induce an RAPD by unequal retinal bleaching ${ }^{16}$ or by off-axis stimulation in patients with strabismus. Patients must not focus on the flashlight since accommodative miosis will be greater when the light is shone in the better eye. Normal subjects may show RAPD up to $3 \mathrm{~dB}$ due to natural asymmetry in pupillomotor drive from the two eyes. ${ }^{17}$ Furthermore, anisocoria will generate RAPDs of approximately $1 \mathrm{~dB}$ for each $1 \mathrm{~mm}$ of anisocoria by limiting the amount of light entering the eye with the smaller pupil. ${ }^{18}$ Media opacities may induce an RAPD in the fellow eye by increasing the scatter and thus the pupillomotor 'effectiveness' of the light stimulus. ${ }^{19}$ Since the test is comparative, it cannot detect bilateral (symmetrical) disease nor can the results be straightforwardly compared between patients.

There are a number of other clinical tests using the PLR to test optic nerve function that have been suggested, but the only one to have enjoyed general popularity is measurement of the pupil cycle time (PCT). Stern ${ }^{20}$ in 1944 first published the observation that if a small beam of light from a slit-lamp is directed into the eye, the subsequent constriction of the pupil turns off the stimulus, leading to pupil dilation that turns the stimulus back on producing endless cycling around this feedback loop. Dysfunction anywhere along the PLR pathway is expected to reduce the frequency of these oscillations and therefore prolong their period. The technique was largely forgotten until it was resurrected and improved by Miller and Thompson in 1978. ${ }^{21}$ They used a horizontal beam $0.5 \mathrm{~mm}$ thick presented tangential to the inferior pupil margin, timed 30 oscillations using a stopwatch, and repeated this five times to give an averaged estimate of what they called the pupil cycle time (expressed in ms). Using this approach, PCT measurements have since been made in patients with a wide variety of optic neuropathies (optic neuritis, ${ }^{22-25}$ compressive optic neuropathy, ${ }^{26,27}$ glaucoma, atrophic papilloedema, traumatic optic neuropathy, and ischaemic optic neuropathy ${ }^{25}$ ).

The technique has the advantages of requiring only a slit-lamp and stopwatch, is simple to perform, and does not require a normal fellow eye for comparison. There are, however, a number of technical and theoretical drawbacks. The test as described by Miller and Thompson takes $5 \mathrm{~min}$, a long time for both patient and clinician to concentrate at the slit-lamp. The background conditions and intensity of stimulus are not standardized. It is difficult or impossible to induce pupillary oscillations in patients with marked optic nerve dysfunction, making it a test most suited to patients with 
mild to moderate disease. The PCT measurement is influenced by resting pupil diameter ${ }^{28}$ and will be prolonged by disease anywhere else in the PLR pathway, invalidating the test in patients with autonomic dysfunction (eg diabetics) or iris abnormalities (eg peripheral iridectomy). Moreover, the sensitivity of the test in detecting optic nerve dysfunction is predicted to be relatively low since most of the delay in the PLR is taken up in the neuro-effector junction at the iris sphincter muscle ${ }^{29}$ rather than in conduction time along the optic nerve. ${ }^{30,31}$ Indeed, Miller and Thompson found that reducing slit beam intensity in normal subjects (effectively simulating the reduced pupillomotor drive of an optic neuropathy) had surprisingly little effect on PCT measurements. When compared with the swinging flashlight test, PCT measurement was found to be less sensitive in detecting mild unilateral abnormalities, ${ }^{32}$ although not all authors have agreed. ${ }^{24}$

\section{Laboratory techniques}

The modern era of pupil research began in 1958 with the development of infrared video pupillography (IVP). ${ }^{33}$ The iris is illuminated by an infrared source and the reflected light imaged by a video camera allowing movements of the pupil to be recorded in darkness. The stimulus parameters can be standardized using electronic photostimulators, and the PLR measurements automated using curve-fitting computer techniques. When comparing the two eyes, the RAPD can be quantified either by alternately stimulating the two eyes and adjusting the stimulus intensity until the response amplitude is the same ${ }^{34}$ or by plotting the stimulus intensity-response amplitude relationship for both eyes and measuring the separation of the two curves. In theory, IVP should also detect an afferent pupil defect in an only eye or where the disease is bilateral and symmetric, but in practice the normal range of PLR amplitudes is frustratingly wide so only moderate to severe optic nerve disease can be confidently diagnosed.

All of the above clinical and laboratory tests use fullfield stimulation to elicit the PLR, that is, the light stimulus illuminates most or all of the fundus and the observed response is the sum of the pupillomotor drive from all areas of the retina. Attempts to measure pupil responses to perimetric light stimuli were first made by Harms in $1949 .{ }^{35}$ Since then there have been a number of attempts to design equipment for performing manual $^{36-41}$ or automated ${ }^{42-45}$ pupil perimetry, and even the M-sequence stimulation techniques from VERIS have been applied to the PLR with some success. ${ }^{46}$ Results so far confirm that defects present in the visual field are generally matched by corresponding defects in the pupil field, suggesting that pupil perimetry has potential as an objective and quantitative means of assessing function in different areas of the visual field.

As research techniques, both IVP and pupil perimetry allow precise characterization of afferent pupil function in optic nerve disorders under controlled conditions, and assessment may be possible in patients unable to perform psychophysical testing. However, these tests rely on sophisticated equipment not generally available to most clinicians, and take time to perform. The spatial resolution in pupil perimetry is poorer than in visual perimetry because larger targets (usually Goldmann size V or $1.7^{\circ}$ ) are needed to elicit pupil responses of sufficient size to measure reliably above the background pupillary 'noise' ${ }^{47}$ However, the greatest limitation to these techniques is the wide range of pupil responses in the normal healthy population. In our experience, PLR gain under physiological conditions varies over more than a two-fold range, and others have also reported a wide variability in the 'normal' amplitude of pupil responses; ${ }^{48-52}$ as a result, individual PLR measurements can only be confidently diagnosed as abnormal by comparison with response amplitudes from the fellow eye or adjacent (unaffected) areas of visual field. When testing single eyes, IVP and pupil perimetry appear to be less sensitive than visual tests in detecting abnormal function in the optic nerve.

\section{Correlation with other indicators of optic nerve function}

\section{Visual tests}

The PLR integrates pupillomotor drive from all areas of the retina. It is of no surprise, therefore, that although RAPDs are usually seen in the eye with the worse acuity, there are numerous situations where the RAPD is found in the eye with the better acuity. ${ }^{53}$ In general, the association between RAPD and visual acuity is poor. As expected, there is a closer correlation between RAPD and visual field loss. Thompson et al ${ }^{54}$ used a weighted template to estimate the total deficit from Goldmann kinetic perimetry and found a reasonable correlation between intereye differences in these estimates and RAPD measurements. More recent studies have confirmed a significant correlation between visual field asymmetry from automated static perimetry and RAPD measurements. ${ }^{55-58}$ Put simply, the bigger the difference in visual field loss the greater the RAPD.

The association between visual function and afferent pupillary function in optic nerve disorders is convenient but not an inevitable consequence of the anatomy. Studies in both cat ${ }^{59}$ and monkey ${ }^{60}$ suggest that the PLR is mostly mediated by the W-class of ganglion cells, 
whereas $\mathrm{X}$ - and Y-cells are responsible for visual perception. The detailed neuroanatomy is not known in humans, but it is possible that when examining patients visual tests and pupil tests give information regarding function in different subpopulations of ganglion cell axons within the optic nerve.

It is interesting then that there are some conditions in which this normally close association breaks down. For example, there have been a number of case reports of apparently normal pupil reactions in patients with Leber's hereditary optic neuropathy. ${ }^{61-63}$ This 'pupil sparing' was confirmed in some later studies ${ }^{64}$ but not in others. ${ }^{65,66}$ The controversy has since been resolved by comparing pupil perimetry and visual perimetry results at corresponding retinal locations; the results confirm that visual field deficits exceed pupil afferent deficits by on average $7.5 \mathrm{~dB}$ at all retinal locations. ${ }^{67}$ A similar degree of pupil-sparing has been found in autosomal dominant optic atrophy ${ }^{68}$ The opposite situation can also arise; we have found that pupil responses remain poor long after visual recovery from demyelinating optic neuritis, ${ }^{69}$ that is, these patients show 'visual sparing'. It seems that the relationship between visual function and pupil function is not constant but varies according to the susceptibility of the different fibre populations to the disease process. ${ }^{70}$

\section{Electrodiagnostic tests}

Abnormalities of the visual-evoked potential (VEP) in optic nerve disease have been described for over 30 years, ${ }^{71}$ but there have been only a few studies comparing these VEP changes with changes in the PLR. Measurements of the RAPD in patients with unilateral anterior ischaemic optic neuropathy (AION $)^{72}$ or optic neuritis ${ }^{73}$ show a reasonably good correlation with the amplitude of the VEP but not its latency. Some authors have predicted that VEP latency should be better correlated with PCT measurements, but only weak associations were found in optic neuritis ${ }^{24,72}$ and none in $\mathrm{AION},{ }^{72}$ presumably because the main influence on PCT is pupillomotor drive not conduction time along the optic nerve. No studies have been published comparing pattern ERG results with the PLR.

\section{Ganglion cell loss}

A number of pieces of indirect evidence suggest that PLR reduction may be linearly correlated with the proportion of nonfunctioning ganglion cells in the retina and optic nerve. In patients with unilateral rhegmatogenous retinal detachments, the magnitude of the RAPD correlates with the extent of the detachment ${ }^{74}$ with each peripheral quadrant contributing about $0.35 \log$ units of RAPD and macular detachment 0.68 log units. ${ }^{75}$ Lagreze and Kardon ${ }^{58}$ used data regarding the distribution of ganglion cells in human retina ${ }^{76}$ to derive templates that, when superimposed on static or kinetic visual fields, give estimates of the percentage loss of ganglion cells: they found that RAPD measurements were strongly and linearly correlated with these estimates across a range of different optic nerve disorders. A number of histopathological studies have estimated the difference in axon counts between the optic nerves of patients showing RAPDs, ${ }^{77,78}$ but in all cases the RAPD was not quantified and so no post hoc evaluation of their relationship is possible. In a monkey model, retinal ablation using diode laser burns produced a threshold RAPD of $0.6 \log$ units when between 25 and $50 \%$ of ganglion cells were lost ${ }^{79}$ (implying that in humans, substantial optic nerve damage may occur before an RAPD is detectable), but unfortunately the relationship between the size of RAPD and degree of further ganglion cell loss was not investigated.

\section{Uses of the pupil in optic nerve evaluation}

\section{Confirming the defect}

The PLR has proved an invaluable clinical tool for establishing whether or not the optic nerve is working normally. In functional visual loss, the absence of an RAPD in patients with apparently unilateral optic neuropathy means that an organic cause is very unlikely, although false negatives can occur if there are media opacities, or if there is marked anisocoria. It has been estimated that a difference in mean defects on Humphrey field analysis of more than $8.7 \mathrm{~dB}$ implies functional loss if there is no detectable RAPD. ${ }^{56}$ Bilateral functional visual loss, especially defects that respect the vertical meridian (hemianopias or quadrantinopias), is becoming increasingly common with the widespread use of automated static perimetry. Organic pathology can be convincingly ruled out by measurement of the PCT or by performing pupil perimetry. ${ }^{80}$ In other patients, pupil signs may be equally important for establishing the organic nature of their visual loss. The presence of an RAPD may be the only objective sign of a retrobulbar optic neuropathy, particularly in patients with demyelinating optic neuritis, traumatic optic neuropathy, or compression of the anterior visual pathways. In cases involving medicolegal disputes the pupil evaluation, especially when supported by measurements using IVP or pupil perimetry, may provide useful objective corroboration of optic nerve dysfunction. 


\section{Quantifying the defect}

Measuring the afferent pupil deficit sometimes has diagnostic value, especially in patients suspected of having dual pathology. For example, patients with unilateral retinal disease confined to the macula rarely show more than $0.5 \log$ units RAPD; ${ }^{81-83}$ if the measured RAPD is substantially greater, then further investigation is warranted to look for another occult cause, for example, compressive optic neuropathy. Tables of expected RAPD values for different pathologies have been published and serve as useful references. ${ }^{84}$ The prognostic value of measuring an RAPD was recently emphasized for traumatic optic neuropathy. It is notoriously difficult to predict outcome in these cases, but the study by Alford et $a l^{85}$ showed that patients with initial RAPD measurements $>2.1 \log$ units have much worse recovery than patients showing less initial RAPD. The value of serial measurements of afferent pupil deficit in patients with chronic optic nerve disorders such as glaucoma, idiopathic intracranial hypertension, or compressive optic neuropathy has not been established but merits study since psychophysical testing is not always reliable or possible in these patients.

\section{Diagnosing the cause}

It has already been mentioned that pupil defects and visual defects do not always match each other in optic nerve disease, and that the direction and extent of this pupillovisual dissociation may vary according to the aetiology. In some cases where the diagnosis is unclear, comparison of visual function and afferent pupil function may help to differentiate between rival diagnoses. For example, pupil-sparing is such a striking feature of Leber's hereditary optic neuropathy that its absence in a patient casts some doubt over this diagnosis as an explanation for the visual loss even in patients harbouring one of the primary mutations. ${ }^{67}$ The value of estimating pupillovisual dissociation in diagnostically uncertain cases has yet to be proven, but as more data become available about pupil involvement in different optic neuropathies, it should be possible to set statistical limits to a putative diagnosis based on the comparison with visual function testing.

\section{Acknowledgements}

I am indebted to Professor Stephen Smith for his enthusiasm and matchless insight into all matters concerning the pupil. Pupil research at the National Hospital is supported in part by the Iris Fund for the Prevention of Blindness.

\section{References}

1 Thompson HS, Corbett JJ. Asymmetry of pupillomotor input. Eye 1991; 5: 36-39.

2 Hirschberg J. Neuritis retrobulbaris. Zentralbl Prakt Augenheilkd 1884; 8: 185-186.

3 Gunn RM. Functional or hysterical amblyopia. Ophthalmol Rev 1902; 21: 271-280.

4 Kestenbaum A. Clinical Methods of Neuro-ophthalmological Investigation, 1st ed. Grune \& Stratton: New York, 1946 pp 281-291.

5 Cox TA. Pupillary escape. Neurology 1992; 42: 1271-1273.

6 Enyedi LB, Dev S, Cox TA. A comparison of the Marcus Gunn and alternating light tests for afferent pupillary defects. Ophthalmology 1998; 105: 871-873.

7 Levatin P. Pupillary escape in disease of the retina or optic nerve. Arch Ophthalmol 1959; 62: 768-779.

8 Thompson HS. Afferent pupillary defects: pupillary findings associated with defects of the afferent limb of the pupil light reflex arc. Am J Ophthalmol 1966; 62: 860-873.

9 Thompson HS. Pupillary signs in the diagnosis of optic nerve disease. Trans Ophthalmol Soc UK 1976; 96: 377-381.

10 Digre KB. Principles and techniques of examination of the pupils, accommodation, and the lacrimal system. In: Miller, Newman (eds). Walsh \& Hoyt's Clinical Neuroophthalmology, 5th ed. 1998 p 941.

11 Thompson HS, Corbett JJ, Cox TA. How to measure the relative afferent pupillary defect. Surv Ophthalmol 1981; 26: $39-42$.

12 Arnold RW. Quantification of the afferent papillary defect by double polarized filter. Arch Ophthalmol 1990; 108: 16661667.

13 Rosenberg ML, Oliva A. The use of crossed polarized filters in the measurement of the relative afferent pupillary defect. Am J Ophthalmol 1990; 110: 62-65.

14 Ramsay A, Williamson TH, Parks S, Keating D. Crossed polarising filters to measure relative afferent pupillary defects: reproducibility, correlation with neutral density filters and use in central retinal vein occlusion. Eye 1995; 9: 624-628.

15 McCormick A, Bhola R, Brown L, Squirrel D, Giles J, Pepper I. Quantifying relative afferent papillary defects using a Sbisa bar. Br J Ophthalmol 2002; 86: 985-987.

16 Thompson HS, Jiang MQ. Letter to the editor. Ophthalmology 1987; 94: 1360-1362.

17 Kawasaki A, Moore P, Kardon RH. Long-term fluctuation of relative afferent pupillary defect in subjects with normal visual function. Am J Ophthalmol 1996; 122: 875-882.

18 Lam BL, Thompson HS. An anisocoria produces a small relative afferent pupillary defect in the eye with the smaller pupil. J Neuro-ophthalmol 1999; 19: 153-159.

19 Lam BL, Thompson HS. A unilateral cataract produces a relative afferent pupillary defect in the contralateral eye. Ophthalmology 1990; 97: 334-338.

20 Stern HJ. A simple method for the early diagnosis of abnormality of the pupillary reaction. Br J Ophthalmol 1944; 28: $275-276$.

21 Miller SD, Thompson HS. Edge-light pupil cycle time. $\mathrm{Br} \mathrm{J}$ Ophthalmol 1978; 62: 495-500.

22 Miller SD, Thompson HS. Pupil cycle time in optic neuritis. Am J Ophthalmol 1978; 85: 635-642.

23 Hamilton W, Drewry RD. Edge-light pupil cycle time and optic nerve disease. Ann Ophthalmol 1983; 15: 714-721. 
24 Kirkham TH, Coupland SG. Multiple regression analysis of diagnostic predictors in optic nerve disease. Can J Neurol Sci 1981; 8: 67-72.

25 Manor RS, Yassur Y, Ben-Sira I. Pupil cycle time in noncompressive optic neuropathy. Ann Ophthalmol 1982; 14: 546-550.

26 Weinstein JM, Van Gilder JC, Thompson HS. Pupil cycle time in optic nerve compression. Am J Ophthalmol 1980; 89: 263-267.

27 Manor RS, Yassur Y, Ben-Sira I. Pupil cycle time in spaceoccupying lesions of anterior optic pathways. Ann Ophthalmol 1982; 14: 1030-1031.

28 Howarth PA, Heron G, Whittaker L. The measurement of pupil cycling time. Graefe's Arch Clin Exp Ophthalmol 2000; 238: 826-832.

29 Terdiman J, Smith JD, Stark L. Pupil response to light and electrical stimulation: static and dynamic characteristics. Brain Res 1969; 16: 288-292.

30 Smith JD, Masek GA, Ichinose LY, Watanabe T, Stark L. Single neuron activity in the pupillary system. Brain Res 1970; 24: 219-234.

31 Barlow RB, Snodderly DM, Swadlow HA. Intensity coding in primate visual system. Exp Brain Res 1978; 31: 163-177.

32 Cox TA, Thompson HS, Hayreh SS, Snyder JE. Visual evoked potential and pupillary signs: a comparison in optic nerve disease. Arch Ophthalmol 1982; 100: 1603-1607.

33 Lowenstein O, Loewenfeld IE. Electronic pupillography: a new instrument and some clinical applications. Arch Ophthalmol 1958; 59: 352-363.

34 Fison PN, Garlick DJ, Smith SE. Assessment of unilateral afferent pupillary defects by pupillography. Br J Ophthalmol 1979; 63: 195-199.

35 Harms H. Grundlagen, Methodik und Bedeutung der Pupillenperimetrie fur die Physiologie und Pathologie des Sehorgans. Graefe's Arch Clin Exp Ophthalmol 1949; 149: 1-44.

36 Burke DW, Ogle KN. Comparison of visual and pupillary light thresholds in periphery. Arch Ophthalmol 1964; 71: 400-408.

37 Bresky R, Charles S. Pupillomotor perimetry. Am J Ophthalmol 1969; 66: 108-112.

38 Narasaki S, Kawai K, Kubota S, Noguchi J. Videopupillographic perimetry and its clinical application. Jpn J Ophthalmol 1974; 18: 253-274.

39 Aoyama T. Pupillographic perimetry. Acta Soc Ophthalmol Japan 1975; 79: 1247-1256.

40 Cibis GW, Campos EC, Aulhorn E. Pupillary hemiakinesia in suprageniculate lesions. Arch Ophthalmol 1975; 93 : 1322-1327.

41 Hellner KA, Jensen W, Muller-Jensen A. Video-processing pupillography as a method for objective perimetry in pupillary hemiakinesia. Doc Ophthalmol 1977; 14: 221-226.

42 Fankhauser F, Flammer J. Puptrak 1.0: a new semiautomated system for pupillometry with the Octopus perimeter. Doc Ophthalmol 1990; 73: 235-248.

43 Alexandridis E, Krastel H. New equipment for pupillographic perimetry. Neuro-ophthalmology 1990; 10: 331-336.

44 Kardon RH, Aydin-Kirkali P, Thompson HS. Automated pupil perimetry: pupil field mapping in patients and normal subjects. Ophthalmology 1991; 98: 485-496.

45 Yoshitomi T, Matsui T, Tanakadate A, Ishikawa S. Comparison of threshold visual perimetry and objective pupil perimetry in clinical patients. J Neuro-ophthalmol 1999; 19: 89-99.
46 Wilhelm H, Neitzel J, Wilhelm B, Beuel S, Ludtke H, Kretschmann U et al. Pupil perimetry using M-sequence stimulation technique. Invest Ophthalmol Vis Sci 2000; 41 1229-1238.

47 Bergamin O, Turtschi S, Schotzau A, Hendrickson Ph, Flammer J, Zulauf M et al. Pupil perimetry with the Octopus 1-2-3: first experience. In: RP Mills, \& M Wall (eds). Proceedings of the XIth International Perimetric Society Meeting. Kugler Publications: Amsterdam/New York, 1995.

48 Schweitzer NMJ. Threshold measurements on the light reflex of the pupil in the dark adapted eye. Doc Ophthalmol 1956; 10: 1-78.

49 Ellis CJK. The pupillary light reflex in normal subjects. $\mathrm{Br} J$ Ophthalmol 1981; 65: 754-759.

50 Kawasaki A, Moore P, Kardon RH. Variability of the relative afferent pupillary defect. Am J Ophthalmol 1995; 120: 622-633.

51 Schmid R, Wilhelm B, Wilhelm H. Pupillomotor campimetry in normals. Neuro-ophthalmology 1999; 23: 7-13.

52 Hong S, Narkiewicz J, Kardon RH. Comparison of pupil perimetry and visual perimetry in normal eyes: decibel sensitivity and variability. Invest Ophthalmol Vis Sci 2001; 42: 957-965.

53 Bullock JD. Relative afferent pupillary defect in the 'better' eye. J Neuro-ophthalmol 1990; 10: 45-51.

54 Thompson HS, Montague P, Cox TA, Corbett JJ. The relationship between visual acuity, pupillary defect and visual field loss. Am J Ophthalmol 1982; 93: 681-688.

55 Brown RH, Zilis JD, Lynch MG, Sanborn GE. The afferent pupillary defect in asymmetric glaucoma. Arch Ophthalmol 1987; 105: 1540 .

56 Johnson LN, Hill RA, Bartholomew MJ. Correlation of afferent pupillary defect with visual field loss on automated perimetry. Ophthalmology 1988; 95: 1649-1655.

57 Kardon RH, Haupert CL, Thompson HS. The relationship between static perimetry and the relative afferent pupillary defect. Am J Ophthalmol 1993; 115: 351-356.

58 Lagreze W-DA, Kardon RH. Correlation of relative afferent papillary defect and estimated retinal ganglion cell loss. Graefe's Arch Clin Exp Ophthalmol 1998; 236: 401-404.

59 Stone J, Fukuda Y. Properties of cat retinal ganglion cells: a comparison of W-cells with X-and Y-cells. J Neurophysiol 1974; 37: 722-748.

60 Leventhal AG, Rodieck RW, Dreher B. Retinal ganglion cell classes in the old world monkey: morphology and central projections. Science 1981; 213: 1139-1142.

61 Nakanishi M, Mashima Y, Hiida Y, Suzuki S, Oguchi Y. Two cases of Leber's hereditary optic neuropathy diagnosed as psychogenic visual loss. Ganka (Ophthalmology) 1994; 36: 811-814.

62 Nikoskelainen EK, Huopenen K, Juvonen V, Lamminen T, Nummelin K, Savontaus ML. Ophthalmologic findings in Leber's hereditary optic neuropathy with special reference to mtDNA mutations. Ophthalmology 1996; 103: 504-514.

63 Bynke H, Bynke G, Rosenberg T. Is Leber's hereditary optic neuropathy a retinal disorder? Report of a case. Neuroophthalmology 1996; 16: 115-123.

64 Wakakura M, Yokoe J. Evidence for preserved direct pupil light response in Leber's hereditary optic neuropathy. Br J Ophthalmol 1995; 79: 442-446.

65 Jakobson DM, Stone EM, Miller NR, Pollock SC, Fletcher WA, McNussen PJ. Relative afferent pupil defects in patients with Leber's hereditary optic neuropathy and unilateral visual loss. Am J Ophthalmol 1998; 126: 291-295. 
66 Ludtke H, Kriegbaum C, Leo-Kottler B, Wilhelm H. Pupillary light reflexes in patients with Leber's hereditary optic neuropathy. Graefe's Arch Clin Exp Ophthalmol 1999; 237: 207-211.

67 Bremner FD, Shallo-Hoffmann J, Riordan-Eva P, Smith SE. Comparing pupil function with visual function in patients with Leber's hereditary optic neuropathy. Invest Ophthalmol Vis Sci 1999; 40: 2528-2534.

68 Bremner FD, Tomlin EA, Shallo-Hoffmann J, Votruba M, Smith SE. The pupil in dominant optic atrophy. Invest Ophthalmol Vis Sci 2001; 42: 675-678.

69 Bremner FD, Tomlin EA, Shallo-Hoffmann J, Smith SE. Poor recovery of the pupil light reflex following acute optic neuritis. Neuro-ophthalmology 2001; 25: 56.

70 Bremner FD, Tomlin EA, Shallo-Hoffmann J, Smith SE. The pupil in optic nerve disease. In: Sharpe JA (ed). 'Neuroophthalmology at the beginning of the new millenium'. Medimond Medical Publications: Englewood, NJ, USA, 2000, pp 23-27.

71 Halliday AM, McDonald WI, Mushin J. Delayed visual evoked responses in optic neuritis. Lancet 1972; 1: 982-985.

72 Cox TA, Thompson HS, Hayreh SS, Snyder JE. Visual evoked potential and pupillary signs: a comparison in optic nerve disease. Arch Ophthalmol 1982; 100: 1603-1607.

73 Ellis CJK. The afferent pupillary defect in acute optic neuritis. J Neurol Neurosurg Psychiatry 1979; 42: 1008-1017.

74 Bovino JA, Burton TC. Measurement of the relative afferent pupillary defect in retinal detachment. Am J Ophthalmol 1980; 90: 19-21.

75 Folk JC, Thompson HS, Farmer SG, O'Gorman TW, Dreyer RF. Relative afferent pupillary defect in eyes with retinal detachment. Ophthalmic Surg 1987; 18: 757-759.
76 Curcio CA, Allen KA. Topography of ganglion cells in human retina. J Comp Neurol 1990; 300: 5-25.

77 Quigley HA, Miller NR, Green WR. The pattern of optic nerve fiber loss in anterior ischaemic optic neuropathy. Am J Ophthalmol 1985; 100: 769-776.

78 Levin PS, Newman SA, Quigley HA, Miller NR. A clinicopathologic study of optic neuropathies associated with intracranial mass lesions with quantification of remaining axons. Am J Ophthalmol 1983; 95: 295-306.

79 Kerrison JB, Buchanan K, Rosenberg ML, Clark R, Andreason K, Altaro DV et al. Quantification of optic nerve axon loss associated with a relative afferent pupillary defect in the monkey. Arch Ophthalmol 2001; 119: 1333-1341.

80 Rajan MS, Bremner FD, Riordan-Eva P. Pupil perimetry in the diagnosis of functional visual field loss. J Roy Soc Med 2002; 95: 498-500.

81 Thompson H, Watzke R, Weinstein J. Pupillary dysfunction in macular disease. Trans Am Ophthalmol Soc 1980; 78: 311-317.

82 Newsome DA, Milton RC, Gass JDM. Afferent pupillary defect in macular degeneration. Am J Ophthalmol 1981; 92 396-402.

83 Folk JC, Thompson HS, Han D, Brown CK. Visual function abnormalities in central serous retinopathy. Arch Ophthalmol 1984; 102: 1299-1302.

84 Kawasaki A, Kardon RH. Disorders of the pupil. Neuroophthalmology 2001; 14: 149-168.

85 Alford MA, Nerad JA, Carter KD. Predictive value of the initial quantified relative afferent pupillary defect in 19 consecutive patients with traumatic optic neuropathy. Ophthal Plast Reconstr Surg 2001; 17: 323-327. 